\title{
Erratum to: Impacts of dam-regulated flows on channel morphology and riparian vegetation: a longitudinal analysis of Satsunai River, Japan
}

\author{
Mayumi Takahashi · Futoshi Nakamura
}

Published online: 17 August 2010

(C) International Consortium of Landscape and Ecological Engineering and Springer 2010

\section{Erratum to: Landscape Ecol Eng}

\section{DOI 10.1007/s11355-010-0114-3}

Due to a publisher's error, Fig. 1 appeared incorrectly in this article. The correct figure is reproduced here. The publisher deeply apologizes for the error.

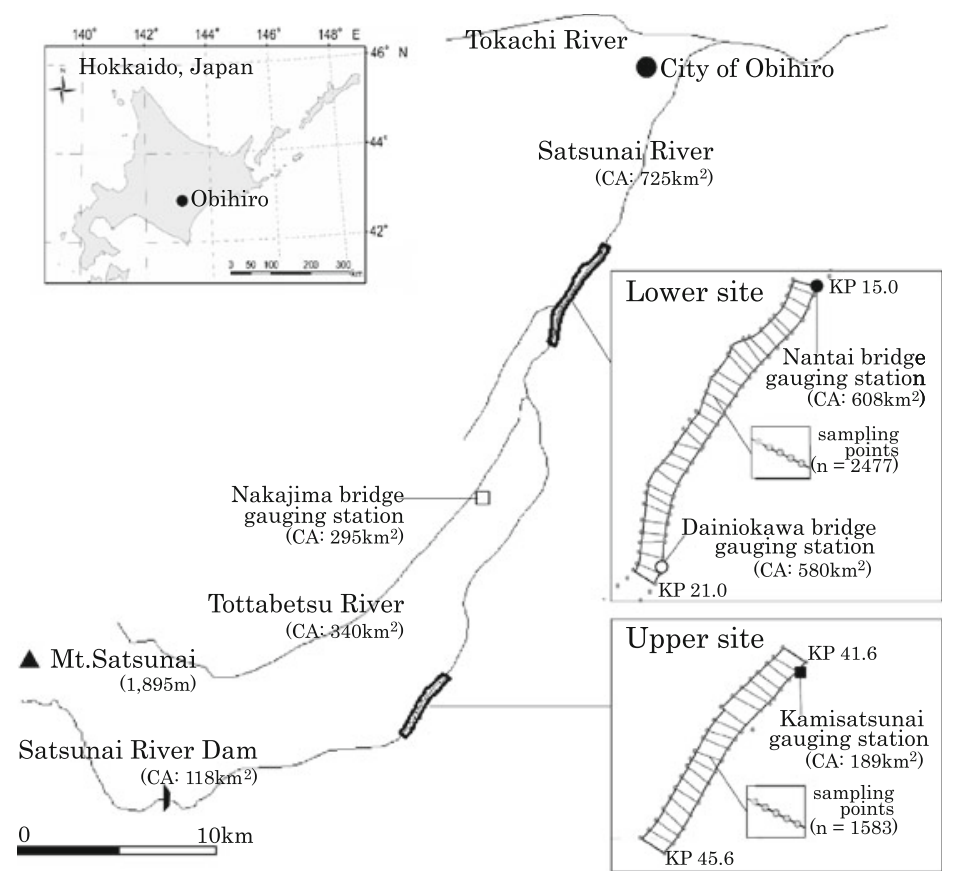

The online version of the original article can be found under doi:10.1007/s11355-010-0114-3.

M. Takahashi $(\bowtie) \cdot$ F. Nakamura

Graduate School of Agriculture, Hokkaido University,

N9W9, Sapporo 060-8589, Japan

e-mail: mayumi92@for.agr.hokudai.ac.jp 